\title{
Multifunctional Teaching Device Based on Augmented Reality Technology Designed for Children With Autism Spectrum Disorders
}

\author{
Tatiana Yurievna Bystrova \\ Professor of Cultural Studies and Design Department \\ Ural Federal University, \\ Yekaterinburg, Russia \\ e-mail: taby27@yandex.ru
}

\begin{abstract}
The paper describes a multifunctional training device created for children with autism spectrum disorders. The device allows diagnosing and conducting corrective and developmental work with such children. A distinctive feature of the described device is the use of augmented reality technology which in the future can serve as a personal "Electronic Tutor".
\end{abstract}

Keywords - augmented reality, virtual reality, hyperreality, autism spectrum disorders.

\section{INTRODUCTION}

There is much evidence that the technology of augmented reality (hereinafter referred to as AR) can serve to enhance the effectiveness of educational processes. Of much importance is AR for children with autism spectrum disorders. Autism spectrum disorders (from this point on referred to as ASD) are a group of complex mental disorders that are characterized by difficulties in social interaction, communication, and stereotyped behavior that children exhibit before the age of 3 [1]. There are indicators that the number of such children is on the rise among global population.

Now we proceed to the description of our idea to create a multifunctional device based on the technologies of augmented reality for children with ASD. The necessary requirements on the device have determined the need for an over-subject approach that uses not only the knowledge of psychology or information technologies, but also key concepts of design and philosophy [2].

Our first research hypothesis can be broadly defined as follows: to create and test a multifunctional educational device for children with ASD it is necessary to consider such characteristics of AR design as the style of graphic images, color combinations, the conscious choice of textures and surfaces, fonts, etc. There are indicators that it is enough not to observe only technological and cost parameters [3, 4], but design features as well. In this case, the concept of design may be referred to not only as design thinking [5], but as the

\author{
Ludmila Valerievna Tokarskaia \\ Associate Professor of Psychological Department \\ Ural Federal University, \\ Yekaterinburg, Russia \\ e-mail: liydmil@mail.ru
}

creation of objective forms according to the laws that are related to human perception $[6,7,8]$.

Our second research hypothesis stems from the idea that for children with ASD it is beneficial to use AR technology rather than to completely "switch" to virtual reality or hyper reality. In other words, it is not advisable to use the phenomenon of presence in full measure because of the excessive psychological overload of a child with ASD and the visual perception features that he has $[9,10]$.

A research into virtual reality has a long history. To date, specialists are actively involved in the use of virtual reality to help people with ASD $[11,12,13,14,15,16,17]$. The surprising fact is that there is a growing body of literature that mainly describe the methods of using virtual reality for children and adolescents with ASD. On the contrary, our device is based on augmented reality technology.

\section{METHODOLOGY}

There is much evidence that for the safe and effective application of an electronic device in the educational and communicative processes of a modern Russian school, it is necessary to initially select the main paradigm settings of the project. This is quite difficult to do because schools and society are at the stage of transformation or, more strictly, at "the point of confusion" $[18,19]$. Classical educational and instructive practices give way to the desire of society and teachers to achieve greater involvement of a child in education, get his/her feedback, generate flexibility of the educational trajectory for greater disclosure of the human potential of each student in all its manifestations [20].

The paper complies with these approaches and the project as a whole stem from the ideas of Russian pedagogy and psychology. There is a strong belief that in the 20th century all these approaches were at the forefront of the world theory of humanities. The works by L. S. Vygotskij [21], S. L. Rubinshtejn [22], G. Altshuller [23] and other authors help to form a theoretical model of a student as a user of our device, avoiding the schematization apparent in some technocratic 
3) Children with autism recognize impossible figures worse.

4) ASD people are less susceptible to certain visual illusions.

5) Children with autism most often look at other people's mouths, accordingly, children with typical development most often look at other people's eyes.

6) ASD children develop limited and repetitive behavior and interests.

The current study found that to compensate for the peculiarities of children with ASD, it is necessary to adhere to a consistent and stable daily routine to prepare the children for the upcoming changes.

The results of the study show that the children with ASD need specially organized activities to establish friendly relations, to develop dialogue skills, and form correct behavior patterns in various social situations. For this, there is a need for long workouts in different situations with different people. In part, such work can be carried out in the conditions of virtual or augmented reality, when the child will train the skill in simulated conditions. The number and variety of such conditions can be selected individually.

The most obvious finding to emerge from the analysis is that it is necessary to control the behavior of a child. The behavior must be channeled to specific interests related to special time slots during the day.

There are indicators that during the process of instructing children with ASD it is possible to use such rewards as candies, cookies, stickers, cards, sensory games, and others.

In order to increase the productivity of a child with ASD, it is necessary to provide him with the most regulated external environment. All tasks must be split into small subtasks supplied with illustrations. It is critical to provide regular feedback and channel the attention of the child in the right direction. The current study showed that these tasks can be well solved in a virtual environment that reduces the number of distractions.

For children with severe attention problems, it is helpful to limit the working time, while using external restraints.

It is interesting to note that in the case of severe motor problems, a child with ASD must be involved in adaptive physical education programs, except for competitive sports. There is enough evidence that a child with ASD can experience difficulties playing team games, since it is difficult for him to understand how to coordinate his actions with the actions of the rest of the team.

Children with ASD may need a highly individualized program to develop writing, reading, and counting skills, while learning time may also be longer. Some children with ASD find it difficult to master writing and they can type texts on a computer or tablet.

Children with ASD, suffering from emotional fragility, need a learning environment in which they can see themselves as competent and successful learners. perform tasks worse that require the integration of disparate fragments of an image (object) into an integral figure. 


\section{THE CORRELATION OF TECHNOLOGY AND DESIGN IN HYPERREALITY}

In current study we proceed from the idea that the design is a "medium" [7], which aligns the technical and human paradigms, providing "productive interaction between man and machine form so that both sides of the process would not lose their essential features" [33]. Alternatively, the user oneself becomes an active link in creating meanings within the space of design. In case of augmented and mixed reality, design can help the user to provide the object with content and helps build associative links. As a result, there is the need for design in the development of virtual projects.

Content design requires careful study of the color palette, lighting characteristics and materials for each of the visual assets placed in the virtual environment [3, 19, 34, 35]. These solutions can be applied both for aesthetic purposes, i.e. using light and material to set the tone for an immersion environment, as well as for functional ones, e.g., using bright colors to alert users about an upcoming action. The same applies to text, fonts, and parameters of physical objects recreated in a virtual environment.

\section{PARAMETERS OF THE TRAINING DEVICE}

The present study indicated that our training device is of much importance for modern global world. The tests of the device are carried within the premises of "Yekaterinburg School № 4" where children with ASD are taught. Simultaneously, we proceeded from the following conceptual diagram of the interaction of a child with ASD with an electronic tutor and other (non-virtual) data medium (Fig. 1).

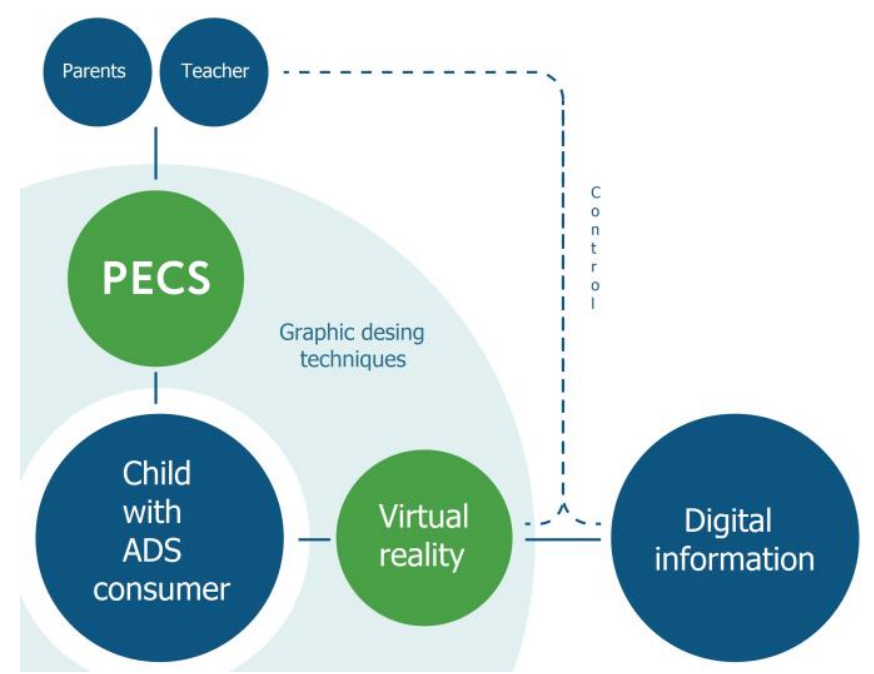

Fig. 1. The process of the interaction of a child with ASD with different types of information. Author: M.A. Nikolaev, 2019.

The system consists of a software part that uses computerbased pattern recognition technology and mobile hardware, i.e. a tablet computer (or augmented reality multimedia glasses).

An interactive educational program clearly demonstrates the order of actions, accompanied by visual and voice prompts. The actions must be carried out to perform a technological operation. Of much importance is the method to interact with children. In our case we developed a special hedgehog character. The expression and appearance of the hedgehog were determined during the demonstration of sketches to children with ASD. This character is responsible for voicing over the device's system.

The training is individual and operates through the demonstration on the monitor of the user's device of additional information layers, including 3D models, hints, animation, text and graphic elements. The device has three modes and allows you to do the following things: 1) to select a geometric shape of the desired size and color and place it in the appropriate hole (attention, knowledge of the simplest geometric shapes); 2) to add a given or arbitrary shape of the proposed elements (combinatorics); 3) to draw a threedimensional image, without touching the monitor with your hand and see it in its entirety (three-dimensional and creative thinking).

It is important that when interacting with a device, a child with ASD can use all channels of perception at the same time, gradually leading to the unity of information that is processed by them discretely. The child can avoid the things which are as follows: to contact with materials that are unpleasant for him and cause his irritation; to repeat the action without delaying other students; to perform the task given only to him, to receive individual voice promotion. In addition, by observing a child, teachers and parents can better understand the picture of their skills and abilities and develop them purposefully in the future.

In addition to the above, in some cases, the device can be used for the diagnosis. The relatively low price, due to the technical improvement of the glasses model, will make it affordable for educational institutions at different levels, as well as for the use at home.

A future better version of the device will be an upgraded device which will be able to perform the functions of the "Electronic Tutor". The tutor will allow you to record various tasks for a child with ASD. The tasks can be played by voice with given parameters. With the help of this device the child will have the opportunity to engage in class conditions in a situation when a teacher is absent. In addition, the device can be used at home, for testing various tasks, as well as to enable parents to switch to solving personal problems.

\section{CONCLUSION}

The current study found that the creation of new products for people with disabilities and, in particular, with ASD cannot occur with the pursuit of exclusively technical goals. Another important finding is that technologies help in solving specific educational, communicative, and orientational tasks only in cases when experts consciously select them, proceeding from a solid scientific basis. The study confirms the idea that technical devices require a through test and adjustment.

The results further support the observation that digital products will not completely force out a human being. However, these results are in accord with recent studies indicating that new educational media will make it possible to offer specially selected tasks for a child as a part of a lesson or 
even a complete lesson. The tasks should be given in a way that is convenient and interesting to a child. This study was able to demonstrate that the most important advantage of technological approaches is the assistance in the formation of an inclusive culture, where each person can find his/her own unique place.

The development findings presented in the paper can be further supplemented using virtual reality tools. There are still many unanswered questions. A further study with more focus on children with ASD and the impact of virtual reality tools on their well-being is suggested.

\section{Acknowledgment}

The article is completed according to the basic research plan for 2020 with the support of the Russian Academy of Architecture and Building Sciences and the Ministry of Construction of Russia in accordance with the State Program of the Russian Federation "Development of Science and Technology" for 2013-2020, the Basic Research Program of the State Academies of Sciences on 2013-2020.

\section{References}

[1] F. Appe. Introduction to the psychological theory of autism [Electronic resource] / Francesca Appe; per. from English D.V. Ermolaeva El. ed. pp. 216, 2013. Date Views 10.09.2017 www.osoboedetstvo.ru/files/book/file/vvedenie_v_psih_teoriyu_autizma .pdf.

[2] J. Illundain-Agurruzza. Holism and the Cultivation of Excellence in Sports and Performance. Skillful Striving. Routledge, New York, London, pp. 368, 2016.

[3] E. Tufty. Envisioning Information. Graphics Press, pp. 128, 1990.

[4] V.M. Bashina. Autism in childhood. Medicine, pp. 240, 1999.

[5] J. Scherer. Krativitaets-techniken. In 10 Schritten Ideen finden, bewerten, umsetzen. Gabal, 2007, pp. 136.

[6] T.Y. Bystrova and L.V. Tokarskaia. "Psychlogical feasibility of design for children with autism spectrum disorders", Lifestyle and Health, iss. 1. pp. 223-235, 2018.

[7] D. Norman. The Design of Everyday Things. Revised and expanded edition. New York: Basic Books, November, 2013, pp. 368.

[8] K. O'Connell, 2016. Designing for Mixed Reality: Blending Data, AR, and the Physical World. O'Reilly Media, 2016, pp. 57.

[9] W. Blackwell. "Autism: Exceptional visual abilities explained", Science Daily, $1, \quad$ April, $2011, \quad$ 10.09.2017. www.sciencedaily.com/releases/2011/04/110404093149.htm.

[10] M. Sigman, T. Mundy, T. Sherman and J. Ungerer. "Social interactions of autistic, mentally retarded and normal children and their caregivers', Journal of Child Psychology and Psychiatry and Allied Disciplines, vol. 27(5), pp. 647-656, 1986.

[11] N. Didehbani, T. Allen, M. Kandalaft, D. Krawczyk and S. Chapman. "Virtual Reality Social Cognition Training for children with high functioning autism", Computers in Human Behavior, vol. 62, pp. 703711, 2016.

[12] L. Fornasari, L. Chittaro and P. Brambilla. "Virtual reality in autism: state of the art", Epidemiology and Psychiatric Sciences, Vol. 20, no. 3, pp. 235-238, September, 2011.

[13] S. Kuriakose and U. Lahiri. "Understanding the Psycho-Physiological Implications of Interaction with a Virtual Reality-Based System in
Adolescents with Autism", A Feasibility Study. IEEE Trans Neural Syst Rehabil Eng., vol. 23(4), pp. 665-75, 2015.

[14] U. Lahiri, E. Bekele, E. Dohrmann, Z. Warren and N. Sarkar. "Design of a virtual reality based adaptive response technology for children with autism", IEEE Trans Neural Syst Rehabil Eng., vol. 21(1), pp. 55-64, 2013.

[15] D. Strickland. 'Virtual reality for the treatment of autism. Stud Health Technol Inform'., vol. 44, pp. 81-86, 1997.

[16] Vision Therapy for Patients with Autism, PDD, Aspergers, or Autism $\begin{array}{llll}\text { Spectrum Disorders. Date } & \text { Views } & \text { D } 03.2017\end{array}$ visioncenter4kids.com/autism.php.

[17] M. Wang, and D. Reid. 'Virtual reality in pediatric neurorehabilitation: attention deficit hyperactivity disorder, autism and cerebral palsy', Neuroepidemiology, vol. 36(1), pp. 2-18, 2011.

[18] Education for a complex society. "Educational ecosystems for social transformation". Global Education Futures report on Forum "Education for a complex world: why, what and how". Global Education Leaders' $\begin{array}{llll}\text { Partnership } & \text { Moscow. } & 2018 . & \text { pp. }\end{array}$ https://futuref.org/educationfutures_ru Data obrashheniya 15.11.2019.

[19] E. Freeman, B. Bates, K. Sierra and E. Robson. Head First Design Patterns. O'Reilly Media, pp. 688, June, 2009.

[20] E. Loshkareva, P. Luksha, I. Ninenko, I. Smagin, D. Sudakov. Skills of the future. What you need to know and be able to do in a complex world.

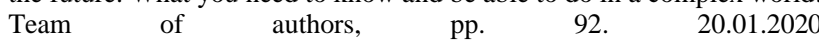
www.files/2017/wsdoklad...okt_rus.pdf

[21] L.S. Vygotskij. Educational psychology, M. Pedagogika Press, pp. 536, 1996.

[22] S.L. Rubinshtejn. Fundamentals of general psychology. - SPb.: Piter, pp. 713,2010

[23] G. S. Altshuller, I. M. Vertkin 'The ideal creative strategy: the concept of maximum upward movement' how to become a genius'. - Minsk: Belarus`, pp. 453 - 468, 1994.

[24] Ch. Fejdl, Byalik M., Trilling B. Four-dimensional education: Kompetencii, competencies needed for success. Skolkovo: w.p. pp. 210.

[25] B. Lowson. How Designers Think. The design process demystified. 4th edition. Elsivier, 2005, pp. 336.

[26] T.Y. Bystrova. Thing, form, style, introduction to the philosophy of design. M.-Ekaterinburg: Desk scientist, pp. 386, 2017.

[27] V.L. Glazychev. Design as it is. M.: Evropa, pp. 320, 2006.

[28] P. Rend, I. Foronova. Art of design / translation from English. M.: Studio publishing house Artemiya Lebedeva, pp. 288, 2015.

[29] N. Duarte Slide:ology. The art of creating outstanding presentations / translation from English by Eleny` Smirnovoj. M.: Izd-vo «Mann, Ivanov i Ferber», pp. 288, 2012.

[30] D. Shervin. Creative workshop. $80 \mathrm{t}$ creative tasks of the designer. SPb.: Piter, pp. 240, 2013.

[31] K.S. Lebedinskaya, O.S. Nikolsksya. Diagnosis of early childhood autism. Initial manifestations. Moscow, Education, pp. 96, 1991.

[32] F. G. E. Happe, U. Frith "The weak coherence account: Detail focused cognitive style in autism spectrum disorders", Journal of autism and developmental disorders. Vol. 36. Iss. 1. pp. 5-25, 2006.

[33] Design Declaration. Date Views 12.11 .2017 worlddesignsummit.com/wpcontent/uploads/2017/10/20171004_WDSM2017_livret40pages_declaration_65X9_AN-1.pdf.

[34] A. Darley, 2000. Visual Digital Culture. Surface play and spectacle in new media genres. Routledge, New York, London.

[35] I. Itten, 1974. The Art of Color. The Subjective Experience and Objective Rationale of Color.Wiley. 